\title{
A study on the relationship between supply chain integration and firm performance
}

\author{
Nahla Al-Nazer ${ }^{a^{*}}$ \\ ${ }^{a}$ Associate Prof of faculty of Business, Department of Business, Middle East University, Amman, Jordan \\ A B S T R A C T \\ Article history: \\ Received December 1, 2021 \\ Received in revised format \\ December 15, 2021 \\ Accepted February 32022 \\ Available online \\ February 32022 \\ Keywords: \\ Supply Chain Integration \\ Firm Performance \\ Stakeholders Pressure \\ Innovation Capability \\ SMES

\begin{abstract}
This study aims to develop a measurement scale for Supply Chain Integration (SCI) and Firm Performance (FP) in Jordanian SMEs. The study instrument was developed based on the previous studies and the survey included 284 companies in Jordan. A sample of 263 responses were used for exploratory analysis. Results show that the 46-item instrument was loaded on four factors. During this phase, the measurement scale was purified to 36 items, and characterized with a high degree of reliability. The results were confirmed using confirmatory factor analysis and showed that the 36-item measurement model met the empirical requirements namely, convergent, construct, and discriminant validity. The fitness indicators test for the model shows that it is applicable in SMEs companies' environment in Jordan. The study presented implications for decision-makers in SMEs companies. The limitation of this study was presented which were relied on to develop directions for future research.
\end{abstract}

\section{Introduction}

Nowadays, many companies are now faced with the challenge of providing advanced products and services to meet the everchanging needs of customers (Fawcett \& Magnan, 2002). However, obtaining this is contingent upon successful acquisition, processing, warehousing and knowledge generation in both internal and external business environments (Ho et al., 2002). As an ideal mechanism for businesses to pursue this agenda strategically (Cao \& Zhang, 2011; Huo, 2012). It connects the information and communication systems of people from different groups so that they can always share information. Empirical research found a strong link between integrating the supply chain and improving the performance of a company (FabbeCostes \& Jahre, 2007). Even though this is true, small businesses in Jordan are not able to benefit from a fully integrated supply chain because they don't have enough money, don't have enough IT, and don't have enough management skills (Ho et al., 2002). It's important to show why it's important for small businesses in Jordan to be involved in the supply chain in order to get the benefits. Furthermore, it's becoming more common for businesses to use creation, which encourages other people to help design and build things. This collaboration can be business-to-customer or business-to-business, but it can be either way (Fabbe Costes \& Jahre, 2007). While the first looks at what customers do, the second looks at how other businesses can help each other create value. Inter-firm value creation lets two or more companies work together to make money while sharing their knowledge and resources (Rivera-Torres, 2013). Inter-firm value co-creation has been found to improve the performance of businesses through the creation of shared value. Further, businesses that integrate their supply chains are more likely to work together to create value for other businesses (Kaufmann \& Carter, 2006). Because Jordan SMEs may not be able to actively participate in the SCI process. (Cao \& Zhang, 2011). Again, the authoritarian traits of most SME owners (unilateral decision making, fear of losing trade secrets, and rivalry) make it less likely that SMEs in Jordan will work together to create value for each other (Martinsuo \& Ahola, 2010). There is a need to find a link between SCI, SP, and FP in Jordan SMEs in

* Corresponding author

E-mail address: nalnazer@meu.edu.jo (N. Al-Nazer)

(c) 2022 Growing Science Ltd. All rights reserved. doi: $10.5267 /$ j.uscm.2022.2.003 
order to get more of them to take part in these strategies. In Jordan, there are more than a dozen small businesses that make and sell a wide range of goods and services (Saad et al., 2002; Alderman \& Ivory, 2007). As a rule, 70\% of all businesses in Jordan are small and medium-sized businesses. This means that economically, this group of businesses helps to create jobs, make money, and come up with new ideas (Humphreys et al., 2003).

Over the last decade, the government of Jordan has made changes to help small businesses make more money (Hartmann \& Caerteling, 2010). To make starting a business easier, these changes encourage the spread of IT information, the provision of training and support, and the availability of financial aid (Gil, 2009, p. 144). While we think these changes will have a big impact on small businesses' participation in SCI and IC, there is still a lot of uncertainty that needs to be investigated (Humphreys et al., 2003). If you want to learn more about this nexus in Jordan, you can't get it from the literature that is out there. To fill in this gap, we look at how SCI and SP, and FP are linked. Another part of our study looks at how innovation capability and stakeholder pressure act as intermediaries between SP and IC and between SCI and FP, as well. Find out how SCI, FP and SP are linked in Jordanian SMEs. Does the ability to come up with new ideas and the pressure from stakeholders play a role in the relationship between SCI and FP, and between SCI and interfirm value creation? We look for the role of stakeholder pressure and innovation capability in mediating the effects of these two factors on management's decisions. This is because the former has an impact on the way managers make decisions, and the latter helps businesses integrate their supply chains and create value together.

Most of the research in Jordan found that SCI has an impact on FP (Brown \& Eisenhardt, 1997). To the best of the authors' knowledge, no research has been done on the impact SCI and FP in Jordan SMES: Testing A Mediation Model. As a result, this study is the first to look at how SCI affects FP through and Innovation Capability. It will also be investigated whether Stakeholders Pressure strengthens the link between SCI and FP. From an SCI standpoint, this will fill the current research gap in emerging SCI literature. Yin, (2003) conducted a study on the impact of SCI on FP and Stakeholders Pressure, Innovation Capability. SCI elements had a direct and indirect effect on FP, according to the researchers. Furthermore, SCI is a significant predictor of FP, but only a few studies have investigated these connections (Caldwell et al., 2009). In addition, previous research has overlooked the important role of Stakeholders Pressure, Innovation Capability as a moderating role between SCI and FP (Zheng et al., 2008). As a result, Stakeholders Pressure, Innovation Capability, are considered mediators and moderators between SCI and FP.

The remainder of the research is organized as follows: The relevant literature of the main constructs is explained first, followed by the hypotheses. The research methodology and data analysis, as well as the research findings, are then presented. Finally, limitations and future research directions are discussed, followed by a discussion of theoretical and managerial implications.

\section{Literature review}

\subsection{Supply Chain Integration}

SCI is where Suppliers and customers in the supply chain work together to share important information about the market, products, customers, and new markets to make smart decisions about how to move forward (Bajari \& Tadelis, 2001). Because good internal structure, culture, and processes are the foundation for any successful collaboration with outsiders, companies with good internal integration can make it easier for SCI with partners to improve organizational effectiveness (Caniëls et al., 2012). SCI has been shown to improve organizational performance in studies (Rönnberg-Sjödin et al., 2011; Gruner and Homburg, 2000). The study looked at 195 Chinese companies, and the findings revealed that strategic alignment of a company's competitive advantage with partners in a SCI is critical to improving financial performance (Ring and van de Ven, 1994). Specifically, SCI helps an organization improve performance by improving customer service and efficiency in its internal operations as well as demand flexibility, new market development, and product development. According to Hicks and McGovern, 2009 studies, Suppliers and customers must be in a good relationship with each other for a company to fully benefit from SCI. Because each stakeholder is motivated toward a common outcome, it is sometimes in the best interest of organizations to enter partnerships with the win-win strategy to help simultaneously support each organization's objective and reap the full potential benefits of the collaboration (Bayliss et al., 2004). Regardless of the benefits derived from SCI partnerships, there are problems that could make them less successful if they aren't properly handled (Eriksson, 2010). Communication breakdowns, insufficient resources, organizational culture and structure, trust issues, strategic objectives that aren't aligned, and unresolved conflicts within an organization all contribute to SCI partnership challenges (Ro et al., 2008). While some of these issues can be traced back to inefficiencies in an organization's internal structure, there are also external threats to consider n (Alderman \& Ivory, 2007). Most importantly, as with the other challenges, the risk of losing trade secrets or accidentally giving away important information to key competitors is a big one. However, the benefits of collaboration are strong enough to make management want to find a way to deal with these looming problems (Brown \& Eisenhardt, 1997). 


\subsection{Supply Chain Integration and Stakeholders Pressure}

Recent research suggests that stakeholder pressure plays a positive role in improving a company's overall performance. Stakeholders are people or groups who have a direct or indirect interest in how an organization does (Gibbert et al., 2008). There are some people who have a financial stake in businesses, but there are also people who want to keep society and the environment safe. Customers, suppliers, competitors, industry associations, local communities, environmental groups, regulators/legislators, media, and shareholders' funds are ten types of outsiders to think about. People in organizations make decisions based on the former more than the latter, except in a few cases when it doesn't make a big difference (Brown \& Eisenhardt, 1997). Consumers, investors, regulatory requirements, and even NGOs can exert pressure on stakeholders. Primary stakeholders are directly or indirectly involved in the shaping of the organization's goals, which leads to profitability and eventually the business's survival, as stated in stakeholder theories (Miles and Huberman, 1994; Langley, 1999; Yin, 2003). Pressure from this group of stakeholders could have an impact on how management decides to implement or not implement the SCI strategy. Evidence shows that pressure from stakeholders can help businesses integrate their supply chains, which could lead to better performance for them (Lu \& Yan, 2007).

\section{H1: SCI efforts have a positive effect on SP.}

\subsection{Stakeholders Pressure and Firm Performance}

According to Dainty et al. (2001) "firm performance" refers to both financial and non-financial aspects of a company. All businesses, regardless of size, location, or service nature, rely on consistent FP to survive and thrive. Non-financial performance, on the other hand, includes things like better partner relationships. As a result, strategic decisions that improve these areas, such as SCI and interfirm value co-creation, are good for business (Leuschner et al., 2013). As a result, we expect Jordanian SMEs to adopt these strategies to improve their financial and non-financial performance. Short-term economic benefits and long-term advantages in the long run are made possible by good supply chain management. Study after study has shown that value creation and FP are linked, but few have fully thought about how this relationship works. (Leuschner et al., 2013). SCI, for example, can make it easier for products and services to be made and delivered in a timely and efficient way. People who work for manufacturers can use accurate information about what customers want and need to speed up product delivery, improve production schedules, and reduce inventory obsolescence with effective SCI (Frohlich \& Westbrook, 2001). As a result, the extent of resource utilization is heavily influenced by a firm's ability to innovate. As a result, we anticipate that SMEs with strong innovative capabilities will significantly improve their performance. A company manages the environment in a progressive way, it will have less internal and external conflicts, which will lead to better FP. Management is under a lot of pressure from stakeholders to make decisions that will help the organization grow both shortterm and long-term (Martinsuo \& Ahola, 2010). Then, discuss how the pressure from shareholders has made the company run better. Determine if there is a link between community stakeholder pressure and the performance of a company. Businesses should set up an environmental management system to improve their environmental performance. Stakeholder pressure and company SCI initiatives were also found to be linked in a good way (Alderman \& Ivory, 2007).

$\mathbf{H}_{2}$ : SP has a positive effect on FP.

H3: SP has a mediating effect on SCI efforts and PF.

\subsection{Supply Chain Integration and Innovation Capability}

The ability of firms to absorb, adapt, and implement technologies to improve the organization's processes and outcomes is referred to as their innovation capability (Briscoe \& Dainty, 2005). Organizational innovation effort has a positive impact on innovation capability and FP, according to the findings. This suggests that activities like interfirm value co-creation and SCI may increase the likelihood of new technologies being adopted by businesses. This is in line with the findings of, which demonstrate that knowledge sharing among internal and external organizational parties promotes innovation Customer and competitor interactions. According to Martinsuo and Ahola, (2010) encourage organizational innovation As a result, activities that encourage these interactions should be encouraged in order to strengthen firms' innovation capabilities. Furthermore, the cordial relationship between internal and external organizational parties greatly improves firms' innovation capability through knowledge sharing activities (Hartmann \& Caerteling, 2010). However, management capabilities and external networking are found to promote innovation within businesses (Kadefors et al., 2007). Insufficient resources and structural rigidity, on the other hand, suffocate initiative within businesses. Furthermore, Organizations with strategic goals are more likely to innovate to improve FP than those without a clearly defined strategy, Technological advancements at businesses. According to Hartmann and Caerteling, (2010) is a critical component of organizational productivity. This demonstrates the importance of SCI and FP in Jordan SMES: Testing A Mediation Model.

H4: SCI efforts have a positive effect on Innovation Capability. 


\subsection{Innovation Capability and firm performance}

SCI and a firm's innovative capability have been shown to positively influence FP empirically. These variables, however, have different effects on FP (Barnes et al., 2007). Furthermore, SCI success and FP are thought to be influenced by the firm's innovative capability. As a result, the nexus between SCI and FP could be explained by innovation capability, which determines how best SCI is executed (Zheng et al., 2008). As a result, we believe that innovation capability influences the relationship between SCI and SMEs' performance in Jordan.

H5: IC has a positive effect on FP.

$\mathbf{H}_{6}$ : IC has a mediating effect on SCI efforts and FP.

Fig. 1 demonstrates the structure of the proposed study.

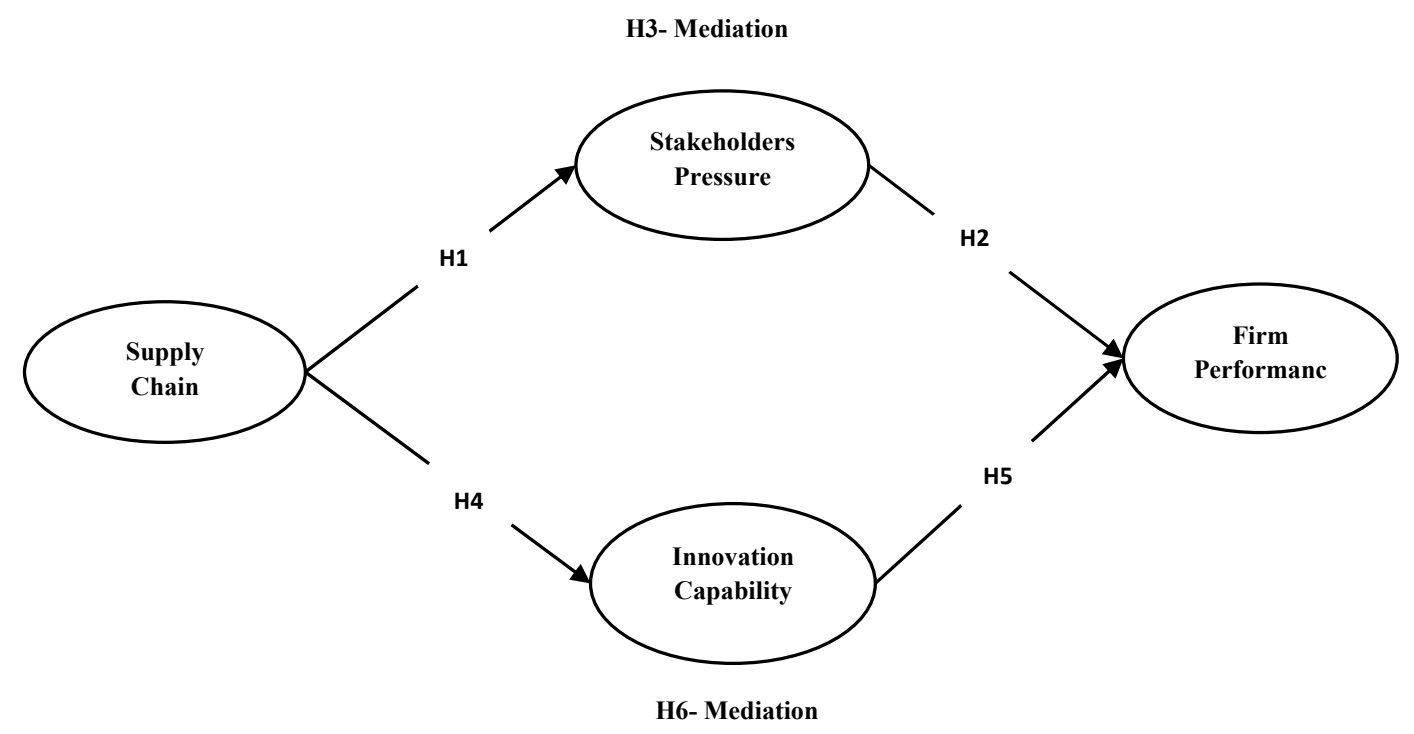

Fig. 1. The proposed model

\section{Research model}

\subsection{Sampling}

The study data were based on a survey that was distributed to companies that conduct SME in Jordan. The questionnaire was initially tested by three executives and four academics, who were asked to review the questionnaire to make sure it was easy to read and identify ambiguities (Dillman, 2000). Several minor amendments were made to the questionnaire, and the questionnaire was then sent to companies in Jordan. Data were obtained from the Small and medium-sized enterprises. The questionnaire was prepared in Arabic and sent to the target sample after a cover letter was developed. Because this study is of a strategic nature, the questionnaire was sent to all levels in the companies. A response of 284 were obtained, among responses there were 21 incomplete responses, which were deleted due to their inappropriateness of analysis. The researcher considered that employees' answers can be considered highly valuable because they are comprehensive if there is no bias in the answers. Accordingly, the total sample analyzed was 263. This study focuses on organizations that practice e-business, all of which are characterized by medium and small size, which means that their activities are not characterized by the complexity that may affect the results compared to large companies. In addition, $78 \%$ of the sample were service companies and $11 \%$ were companies selling and buying electronically. The remaining $11 \%$ were industrial companies from different sectors such as beverages, chemical industries, electronic equipment, furniture industry and food industries. The non-response bias was confirmed to test for significant differences among respondents. To ensure the adequacy of the data, two sets of data were compared at an early stage of the study, and T tests were used on all 21 questionnaire questions. The results of the Chisquare test showed no statistically significant differences between the two sets of data. Consequently, the results suggest that non-response bias in the data does not exist.

\subsection{Constructs of the measurement scale}

A four model factors were developed, and multiple variables used to measure each factor. Scale items were developed from previous studies. The first factor measures supply chain integration. The Porter study (1985) was used to measure the various variables of supply chain integration. These variables were repeated in many studies later, and these dimensions can be considered comprehensive and are used in many studies that measure economic indicators. Five items were used to evaluate 
SCI for the company, cost effectiveness, increasing sales / profits, getting cheaper raw materials, efficient machines, efficient supply chain management systems, saving time and energy, competitive market and maximizing profits, building links with suppliers and channels, improve inter-relationships with other business units within a firm. Factor 2 included 6 items to evaluate FP. These items evaluate the ability of SCI companies for increasing a company performance, Financial, Business education projects, sponsoring community development trusts, Civic improvement, Supporting progress for good governance etc., (Snider, Hill, \& Martin, 2003; Zairi \& Peters, 2002). A total of 12 items for Stakeholder's pressure were adapted from (Zairi \& Peters, 2002) 10 items external, 2 items internal. Finally, the factor of Innovation capability was adapted from Maçada et al., (2012). These items are not new and have been used in the past and studies (Brynjolfsson \& Hitt, 1996; Kohli \& Devaraj, 2003; Saloojee et al., 2007). All developed measurement scales used a five-point Likert scale where 1: strongly disagree and 5: strongly agree.

\section{Results}

The purpose of this study is to investigate the nexus between SCI and FP mediation influence of Stakeholders Pressure, Innovation Capability. The proposed moderated mediation model was tested using structural equation modeling (SEM) with maximum likelihood estimation to attain the aforementioned purpose. Structural equation modeling (SEM) is an appropriate technique to measure various direct, moderating, and mediating relationships among constructs (Hair et al., 2010). AMOS 23.0 software was used to examine this model.

\subsection{Measurement model}

According to Anderson and Gerbing (1988), confirmatory factor analysis (CFA) was performed to test the construct reliability and validity of the measurement models using AMOS 23 software. The measurement model indicated acceptable model fit $(\chi 2=265.982, \mathrm{df}=142, \chi 2 / \mathrm{df}$

$=1.873, \mathrm{p}=.000<.001$, goodness-of-fit index $(\mathrm{GFI})=.906 \geq 0.90$, normed-fit index $(\mathrm{NFI})=.905 \geq 0.90$, confirmatory fit index $(\mathrm{CFI})=.953 \geq 0.90$, Tucker-Lewis index $(\mathrm{TLI})=.943 \geq 0.90$, and root-mean-square error of approximation (RMSEA) $=.058 \leq 0.08$. Figure 1 demonstrates the measurement model by CFA with standardized factor loadings.

\subsection{Reliability and validity}

Cronbach's alpha and composite reliability scores were used to measure the reliability of all the constructs in the measurement model. When the Cronbach's alpha and composite reliability (CR) scores are higher above the specified cut-off value of 0.7 , the construct is considered reliable. (Hair et al., 2010). Table 2 showed that all the scales' CR and Cronbach's alpha values were found to meet the required threshold criterion, indicating that they are all reliable. Additionally, convergent validity and discriminant validity were also assessed for each construct. If the average variance extracted (AVE) estimations for each construct reach the specified cut off value of 0.50 , convergent validity is supported (Hair et al., 2010). AVE values are demonstrated in Table 2 range from 0.526 to 0.744 which provides further evidence for convergent validity among constructs. Lastly, if the square root of each construct's AVE value is larger than the correlations with the other constructs, indicating adequate discriminant validity (Fornell \& Larcker, 1981). Table 3 demonstrates that the square root of the AVE value of each construct was greater than other constructs, confirming the distinctiveness of five (05) constructs. Thus, it can be said that the measurement model showed the sufficient robustness required to examine the link between the constructs through the structural model.

Table 1

The results of CFA

\begin{tabular}{|c|c|c|c|c|c|}
\hline Constructs & Items & $\begin{array}{l}\text { Factor Loadings } \\
\text { (Standardized) }\end{array}$ & AVE & CR & Cronbach $\alpha$ \\
\hline \multirow{5}{*}{ Supply chain integration } & SCI1 & 0.829 & \multirow{5}{*}{0.526} & \multirow{5}{*}{0.846} & \multirow{5}{*}{0.839} \\
\hline & SCI 2 & 0.805 & & & \\
\hline & SCI 3 & 0.659 & & & \\
\hline & SCI 4 & 0.698 & & & \\
\hline & SCI 5 & 0.612 & & & \\
\hline \multirow[t]{3}{*}{ Stakeholders Pressure } & SP1 & 0.787 & \multirow{3}{*}{0.653} & \multirow{3}{*}{0.850} & \multirow{3}{*}{0.848} \\
\hline & SP 2 & 0.834 & & & \\
\hline & SP 3 & 0.803 & & & \\
\hline \multirow{3}{*}{ Innovation Capability } & $\mathrm{IC} 1$ & 0.755 & \multirow{3}{*}{0.593} & \multirow{3}{*}{0.814} & \multirow{3}{*}{0.813} \\
\hline & IC 2 & 0.765 & & & \\
\hline & IC 3 & 0.790 & & & \\
\hline \multirow{4}{*}{ Firm Performance } & FP1 & 0.844 & \multirow{4}{*}{0.534} & \multirow{4}{*}{0.819} & \multirow{4}{*}{0.817} \\
\hline & FP 2 & 0.770 & & & \\
\hline & FP 3 & 0.655 & & & \\
\hline & FP 4 & 0.633 & & & \\
\hline
\end{tabular}


Table 2

The summary of the results of the correlations

\begin{tabular}{|c|c|c|c|c|c|}
\hline Latent Variables & $\begin{array}{c}\text { Social Media } \\
\text { Marketing Efforts }\end{array}$ & $\begin{array}{c}\text { Customer Brand } \\
\text { Engagement }\end{array}$ & Brand Attitude & Brand Trust & $\begin{array}{c}\text { Overall Brand } \\
\text { Equity }\end{array}$ \\
\hline Supply chain & 0.725 & & & & \\
\hline Stakeholders Pressure & .242 & 0.808 & & & \\
\hline Innovation Capability & .542 & .289 & 0.770 & & \\
\hline Firm Performance & .366 & .312 & .464 & .299 & 0.731 \\
\hline
\end{tabular}

Notes: Italicised elements (Bolded) are the square root of AVE for each construct

\subsection{Structural model assessment and hypotheses testing}

After attaining the reliability and validity of the measurement models, a covariance-based structural equation model (SEM) using AMOS 23 was performed and the results show all the fit indices in the satisfactory range. The fit indices are GFI $=.924$ , $\mathrm{CFI}=0.954, \mathrm{NFI}=.908, \mathrm{TLI}=.944, \mathrm{RMSEA}=0.058$ which represent appropriateness of the structural model. The results of the direct paths are presented in Table 3. The results of path analysis illustrate that SMM efforts have a significant positive effect on customer brand engagement and brand attitude $(\beta=.263, p=.000<.001 ; \beta=.566, p=.000<.001)$, supporting H1 and H5. Likewise, customer brand engagement and brand attitude have a substantial direct impact on overall brand equity $(\beta=.188, \mathrm{p}=.003<.01 ; \beta=.394, \mathrm{p}=.000<.001)$, supporting $\mathrm{H} 2$ and $\mathrm{H} 6$.

\subsection{Discriminant validity results}

Table 3 summarizes the results of the discriminant validity.

Table 3

The summary of the discriminant validity

\begin{tabular}{|c|c|c|c|c|}
\hline Path & $\beta$ & S.E. & C.R. & $\mathbf{P}$ \\
\hline $\mathrm{SP} \leftarrow \mathrm{SCI}$ & .263 & .073 & 3.588 & $* * *$ \\
\hline $\mathrm{IC} \leftarrow \mathrm{SCI}$ & .566 & .077 & 7.372 & $* * *$ \\
\hline $\mathrm{FP} \leftarrow \mathrm{SP}$ & .188 & .063 & 2.975 & .003 \\
\hline $\mathrm{FP} \leftarrow \mathrm{IC}$ & .394 & .069 & 5.723 & $* * *$ \\
\hline
\end{tabular}

Note(s): ${ }^{*} \mathrm{p}<0.05, * * \mathrm{p}<0.01, * * * \mathrm{p}<0.001$

\subsection{Mediation analysis}

Bootstrapped bias-corrected confidence intervals (CIs) were conducted for 5000 resamples with a $95 \%$ confidence interval to test the significance of the mediation effects. Results demonstrated in Table 4 confirm that SP mediates between the relationship of SCI and FP $(\beta=.049, p=.004$, bias-corrected $95 \% \mathrm{CI}: 0.014,0.121)$, supporting H3. Also, IC partially mediates between the relationship of SCI efforts and $\operatorname{OBE}(\beta=.223, p=.000$, bias-corrected $95 \%$ CI: $0.084,0.470)$, accepting H6.

Table 4

$\underline{\text { Results of mediation analysis }}$

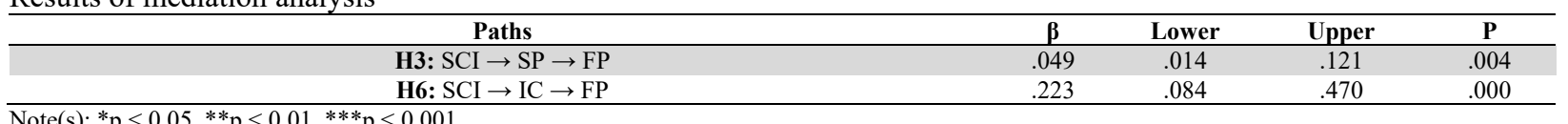

\section{Discussion and implications}

Many researchers face pressure to answer questions about SCI. There has been growing debate about the negative effects of using information technology in business (Walters, 2007). Although the research orientations seek to highlight the role of SCI as a positive influence in the FP, now this topic remains the focus of many controversial debates. Many studies argue that attention to SCI and FP contributes significantly to influencing SMEs companies (Sikdar, 2003; Kaufmann \& Carter, 2006). There are those who say that to achieve value for business in general, and SCI, it is necessary to focus on the four aspects of strength, scope, duration, and depth of integration (Porter, 2011). For example, interest in the community helps to improve the image and reputation of the company, facilitate the marketing of company products and services, and increase the effectiveness of the company in achieving its goals as a company interested in the community. On the other hand, the interest in the SCI also contributes to improving the image of the company as a supporter of the sustainability of various resources. The company can produce products and market them as environmentally friendly products, thus increasing their profits. When the company adopts a biodegradable and recyclable approach. All these factors increase the awareness of customers and employees that contributes significantly to the purchase of its products.

Results have shown that SCI can be considered independent factors. The results of the covariance test showed no high correlation between the four factors, and the multicollinearity in the measurement model is absent (Hair et al., 2010). This suggests that any of the four factors can affect the SMEs if its impact is measured independently. This helps practitioners and planners in SMEs in Jordan to deal with each dimension alone, directing development policies to improve that performance individually, and each type of performance can be measured individually. This will identify gaps in performance and guide strategic plans to effectively improve FP. In addition, the absence of multicollinearity in the measurement model and the fact 
that each of the SCI factors are independent can measure the impact of the FP. The impact of Stakeholders Pressure and Innovation Capability on FP as a mediator variable can also be measured in influencing the SMEs. All items in the measurement model have been consistent with many previous studies which have been relied upon to create the questionnaire items (Porter, 1985; Snider, Hill, \& Martin, 2003; Kohli and Devaraj, 2003), indicating that the items of the measurement model that have been confirmed in this study have been applied in many previous studies. Many studies (e.g Porter, 1985) have suggested that SCI can be integrated, indicating the possibility of building a conceptual model to measure these dimensions together. Also, many studies pointing to the impact of SCI in creating value for business (e.g., Kaufmann \& Carter, 2006). In addition to many studies that focused on the role of Stakeholders Pressure and Innovation Capability in achieving excellent profits. Based on the above, the researchers hypothesized a conceptual model that suggests that SCI indicators and FP can be assumed within a single conceptual model.

Finally, the results of the confirmatory factor analysis did not support the SCI, while emphasizing Stakeholders Pressure and Innovation Capability. Unlike the study of Maçada et al., (2012), which excluded the value of infrastructure. As mentioned above, the study of Maçada et al., (2012) was conducted in an SCI that differed in its characteristics from the SMEs, and also in another country. Many of the surveyed managers gave a great importance to the dimension of infrastructure as the actual use of SMEs has not yet reached maturity. This requires intensive investment in the Small and medium-sized enterprises (SMEs) to accelerate development. This also explains that the results have supported the SP in the measurement model. Because managers are not convinced that this variable can be measured now or might be considered an independent factor. Managers cannot recognize the benefits of Innovation Capability to SMEs in corporate activities, such as developing business plans, expanding organizational capabilities, improving business models, and developing staff capabilities.

\section{Limitations and future research}

There are several limitations of this study to be observed, as well as guidelines for future research. First, this study focused on the development of the measurement model because of the absence of a general conceptual framework containing the four dimensions in the theoretical literature in the field of SMEs. Researchers believe that a conceptual framework for how to SCI for SMEs by focusing on FP has been studied or matured with different factors. Based on this, researchers have developed the measurement model in this research. Accordingly, the study recommends that future research should be directed to measure the impact of SCI for business in general and SMEs in particular. This can be conducted by building a structural model that includes the impact of SCI on FP. The impact of Innovation Capability and Stakeholders Pressure can be tested as a mediate variable of the relationship between SCI and FP in influencing SMEs and measuring the direct and indirect impacts of the model. Second, this study was applied in the SMEs sector, therefore, it is difficult to generalize the results of this study to the rest of the business sectors. The measurement model that has been developed can serve in the Small and medium-sized enterprises (SMEs) sector, other sectors differ in their characteristics. In some sectors, the importance of SCI is particularly significant, especially in manufacturing industries due to many environmental and social concerns. The study recommends that future research should be directed to study the rest of the different business sectors in order to ensure that the results can be generalized, and the concepts associated with FP are dependent. Finally, the sample focused on managers in the top of business companies due to the strategic nature of this study. Usually, samples obtained from managers are few. This also makes it difficult to generalize the results of the study. The study also recommends expanding the scope of the research samples and including of employees, as well as those involved in the work of companies such as shareholders, stakeholders (consumers, governments, etc.), and other parties within the supply chain who are also responsible for the stages of creating value for business.

\section{Acknowledgments}

The authors are grateful to the Middle East University, Amman, Jordan for the financial support granted to cover the publication fee of this article.

\section{References}

Alderman, N., \& Ivory, C. (2007). Partnering in major contracts: Paradox and metaphor. International Journal of Project Management, 25(4), 386-393.

Anderson, J. C., \& Gerbing, D. W. (1988). Structural equation modeling in practice: A review and recommended two-step approach. Psychological bulletin, 103(3), 411.

Bajari, P., \& Tadelis, S. (2001). Incentives versus transaction costs: A theory of procurement contracts. Rand journal of Economics, 387407.

Barnes, B. R., Naudé, P., \& Michell, P. (2007). Perceptual gaps and similarities in buyer-seller dyadic relationships. Industrial Marketing Management, 36(5), 662-675.

Bayliss, R., Cheung, S. O., Suen, H. C., \& Wong, S. P. (2004). Effective partnering tools in construction: a case study on MTRC TKE contract 604 in Hong Kong. International Journal of Project Management, 22(3), 253-263.

Briscoe, G., \& Dainty, A. (2005). Construction supply chain integration: an elusive goal? Supply Chain Management: International Journal, 10(4), 319-326.

Brown, S. L., \& Eisenhardt, K. M. (1997). The art of continuous change: Linking complexity theory and time-paced evolution in relentlessly shifting organizations. Administrative Science Quarterly, 42(1), 1-34. 
Brynjolfsson, E., \& Hitt, L. (1996). Paradox lost? Firm-level evidence on the returns to information systems spending. Management science, 42(4), 541-558.

Caldwell, N. D., Roehrich, J. K., \& Davies, A. C. (2009). Procuring complex performance in construction: London Heathrow Terminal 5 and a Private Finance Initiative hospital. Journal of Purchasing and Supply Management, 15(3), 178-186.

Caniëls, M. C., Gelderman, C. J., \& Vermeulen, N. P. (2012). The interplay of governance mechanisms in complex procurement projects. Journal of Purchasing and Supply Management, 18(2), 113-121.

Cao, M., \& Zhang, Q. (2011). Supply chain collaboration: impact on collaborative advantage and firm performance. Journal of Operational Management, 29(3), 163-180.

Dillman, D. A. (2000). Procedures for conducting government-sponsored establishment surveys: Comparisons of the total design method (TDM), a traditional cost-compensation model, and tailored design. In Proceedings of American Statistical Association, Second International Conference on Establishment Surveys (pp. 343-352).

Eriksson, P. E. (2010). Improving construction supply chain collaboration and performance: a lean construction pilot project. Supply Chain Management: An International Journal, 15(5), 394-403.

Fabbe-Costes, N., \& Jahre, M. (2007). Supply chain integration improves performance: the Emperor's new suit?. International Journal of Physical Distribution \& Logistics Management, 37(10), 835-855.

Fawcett, S. E., \& Magnan, G. M. (2002). The rhetoric and reality of supply chain integration. International Journal of Physical Distribution \& Logistics Management, 32(5), 339-361.

Fornell, C., \& Larcker, D. F. (1981). Structural equation models with unobservable variables and measurement error: Algebra and statistics.

Frohlich, M. T., \& Westbrook, R. (2001). Arcs of integration: an international study of supply chain strategies. Journal of Operations Management, 19(2), 185-200.

Gibbert, M., Ruigrok, W., \& Wicki, B. (2008). What passes as a rigorous case study?. Strategic management journal, 29(13), 1465-1474.

Gil, N. (2009). Developing cooperative project client-supplier relationships: How much to expect from relational contracts?. California Management Review, 51(2), 144-169.

Gruner, K. E., \& Homburg, C. (2000). Does customer interaction enhance new product success?. Journal of Business Research, 49(1), 114.

Hartmann, A., \& Caerteling, J. (2010). Subcontractor procurement in construction: the interplay of price and trust. Supply chain management: an international journal, 15(5), 354-362.

Hicks, C., \& McGovern, T. (2009). Product life cycle management in engineer-to-order industries. International Journal of Technology Management, 48(2), 153-167.

Ho, D. C., Au, K. F., \& Newton, E. (2002). Empirical research on supply chain management: a critical review and recommendations. International journal of production research, 40(17), 4415-4430.

Humphreys, P. K., Wong, Y. K., \& Chan, F. T. S. (2003). Integrating environmental criteria into the supplier selection process. Journal of Materials processing technology, 138(1-3), 349-356.

Huo, B. (2012). The impact of supply chain integration on company performance: an organizational capability perspective. Supply Chain Management: An International Journal, 17(6), 596-610.

Kadefors, A., Björlingson, E., \& Karlsson, A. (2007). Procuring service innovations: Contractor selection for partnering projects. International Journal of Project Management, 25(4), 375-385.

Kaufmann, L., \& Carter, C. R. (2006). International supply relationships and non-financial performance-a comparison of US and German practices. Journal of Operations Management, 24(5), 653-675.

Kohli, R., \& Devaraj, S. (2003). Measuring information technology payoff: A meta-analysis of structural variables in firm-level empirical research. Information systems research, 14(2), 127-145.

Leuschner, R., Rogers, D. S., \& Charvet, F. F. (2013). A meta-analysis of supply chain integration and firm performance. Journal of Supply Chain Management, 49(2), 34-57.

Lu, S., \& Yan, H. (2007). A model for evaluating the applicability of partnering in construction. International journal of project management, 25(2), 164-170.

Maçada, A. C. G., Beltrame, M. M., Dolci, P. C., \& Becker, J. L. (2012). IT business value model for information intensive organizations. BAR-Brazilian Administration Review, 9(1), 44-65.

Martinsuo, M., \& Ahola, T. (2010). Supplier integration in complex delivery projects: Comparison between different buyer-supplier relationships. International Journal of Project Management, 28(2), 107-116.

Miles, M., \& Huberman, M. (1994). Qualitative Data Analysis. 2. Sage publications, London.

Porter, M. E. (1985). Technology and competitive advantage. Journal of business strategy, 5(3), 60-78.

Ro, Y. K., Liker, J. K., \& Fixson, S. K. (2008). Evolving models of supplier involvement in design: The deterioration of the Japanese model in US auto. IEEE Transactions on Engineering Management, 55(2), 359-377.

Rönnberg Sjödin, D., Eriksson, P. E., \& Frishammar, J. (2011). Open innovation in process industries: a lifecycle perspective on development of process equipment. International Journal of Technology Management, 56(2/3/4), 225-240.

Saad, M., Jones, M., \& James, P. (2002). A review of the progress towards the adoption of supply chain management (SCM) relationships in construction. European Journal of Purchasing \& Supply Management, 8(3), 173-183.

Sikdar, S. K. (2003). Sustainable development and sustainability metrics. AIChE journal, 49(8), 1928-1932.

Saloojee, G., Phohole, M., Saloojee, H., \& IJsselmuiden, C. (2007). Unmet health, welfare and educational needs of disabled children in an impoverished South African peri-urban township. Child: care, health and development, 33(3), 230-235.

Zairi, M., \& Peters, J. (2002). The impact of social responsibility on business performance. Managerial Auditing Journal, 17(4), 174-178.

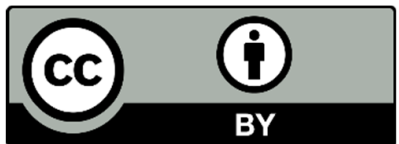

(C) 2022 by the authors; licensee Growing Science, Canada. This is an open access article distributed under the terms and conditions of the Creative Commons Attribution (CC-BY) license (http://creativecommons.org/licenses/by/4.0/). 